\title{
Reflections on the Journal of Micro/Nanopatterning, Materials, and Metrology's First Year
}

\author{
Harry J. Levinson \\ Editor-in-Chief
}

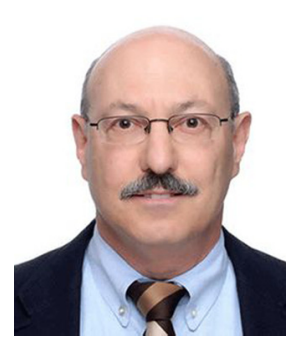

At the beginning of 2021, a plan that had long been in the making was executed, and SPIE's Journal of Micro/Nanolithography, MEMS, and MOEMS was split into two parts. One piece became the Journal of Optical Microsystems, focused on the science and engineering of integrated photonic and optical systems, while the other became the current $\mathrm{JM}^{3}$, the Journal of Micro/Nanopatterning, Materials, and Metrology - this journal.

Much of the work to make $\mathrm{JM}^{3}$ a high-quality journal is done by our senior and associate editors. Since most of the people serving on the $\mathrm{JM}^{3}$ editorial board in 2021 had been supporting our journal previously, their continuing contributions ensured a smooth transition at the beginning of last year. During 2021, a few new associate editors were added to the editorial board in order to bring expertise in subjects that are newly relevant to patterning technology or that have increased in significance in recent years. Our current editorial board is listed in Table 1.

Table 1

\section{Senior Editors}

Martin Burkhardt (IBM Corp., USA)

Moshe Preil (Carl Zeiss. Inc., USA)

Steven Hansen (ASML, USA)

Martha Sanchez (LytEn. Inc., USA)

Associate Editors

Vivek Bakshi (EUV Litho Inc., USA)

Catherine Labelle (Intel, USA)

Xuemei Chen (KLA, USA)

Lars Liebmann (Intel, USA)

Chris Clifford (Siemens, USA)

Qinghuang Lin (Lam Research, USA)

Ralph Dammel (EMD Performance Materials, USA)

Uzodinma Okoroanyanwu (University of Massachusetts, Amherst, USA)

Danilo De Simone (imec, Belgium)

Leo Pang (D2S, USA)

Yasin Ekinci (Paul Scherrer Institute, Switzerland)

Danping Peng (TSMC, USA)

Hiroshi Fukuda (Hitachi High Technologies, Corp., Japan)

Douglas J. Resnick (Canon Nanotechnologies, Inc., USA)

Emily Gallagher (imec, Belgium)

Kurt Ronse (imec, Belgium)

Greg Gallatin (ASML, USA)

Daniel G. Smith (Nikon Research, Corp., USA)

Roel Gronheid (KLA, Belgium)

Alexander Starikov (I\&I Consulting, USA)

Erik R. Hosler (PsiQuantum, LLC, USA)

Bo Su (D2S, USA)

Ryoung-han Kim (imec, Belgium)

Yayi Wei (Chinese Academy of Sciences, China)

Seong Sue Kim (Yonsei University, Republic of Korea)

(1) 2022 Society of Photo-Optical Instrumentation Engineers (SPIE) 
Table 2

\begin{tabular}{ll}
\hline \hline Special Section or Series Title & \multicolumn{1}{c}{ Guest Editors } \\
\hline EUV Masks & Martin Burkhardt and Vicky Philipsen \\
Masks and Lithography in the Era of Multi-beam Mask Writers & Alan Brodie and Martha Sanchez \\
Deep Learning for Lithography and Photomask Applications & Leo Pang \\
\hline \hline
\end{tabular}

Notably during 2021 there were two special sections and one special series, compared to none during the prior year, as shown in Table 2. Nearly half of the papers published in $\mathrm{JM}^{3}$ in 2021 were in special sections. Creating a special section requires more work on the part of the editors than normal submissions, because a call for papers needs to be generated and contributions solicited. It should be noted that three of the guest editors are also on the editorial board, so they were doing double duty to serve the patterning community.

For a peer-reviewed journal such as $\mathrm{JM}^{3}$, it is expected that a significant amount of information be included by authors in their papers. However, $\mathrm{JM}^{3}$ serves engineers and scientists in industry, and the need for companies and many research institutes to protect certain information is recognized. Accordingly, a set of guidelines was generated in 2021 to provide guidance to authors, editors, and reviewers for balancing between disclosure typical for a peer-reviewed journal and the needs of people in industry. These were published in a series of editorials in $\mathrm{JM}^{3}$ during the past year, and they are included in the overall guidelines for authors.

Our technical community is fortunate to have a committed staff at SPIE for assistance and support. All that was accomplished in 2021 resulted from the efforts of SPIE staff, who continued to provide excellent support to editors, authors, and reviewers.

With a good start in 2021, it is hoped that the Journal of Micro/Nanopatterning, Materials, and Metrology will continue the tradition of quality established by prior journals that went by the acronym $\mathrm{JM}^{3}$, and that this journal will remain a valuable resource for the community of engineers and scientists in the semiconductor industry who are involved with patterning technology. 